In nature, magnesium compounds are distributed in the form of such minerals as dolomite, magnesite, serpentinite, brucite, and in the form of such solutions as sea and ocean waters, salt lakes, bischofite. The main popular magnesium compounds are its chloride, hydroxide, and oxide. The most common technology for obtaining magnesium hydroxide is based on the action of alkaline reagents on solutions of magnesium. However, the technology has significant drawbacks. The main issue is that magnesium hydroxide cannot be obtained free of impurity metal ions, and the sediment itself has an extremely low filtration rate from the solution in which it is formed.

Magnesium hydroxide is an excellent sorbent collector for the ions of most metals, so it is possible to utilize this property of absorption of magnesium hydroxide to produce other highly pure compounds, for medicine and pharmacopeia. This paper investigates the processes of alkaline hydrolysis of magnesium chloride and the formation of magnesium hydroxide sediment, the kinetics of processes, as well as the properties of sediments. Empirical formulas for sediment production parameters with a high filtration coefficient that exceeds the known values of $1 \cdot 10^{6}$ have been derived. The study reported here hasrevealed the possibility of obtaining in a relatively simple way highly pure chloride, hydroxide, and magnesium oxide, sodium chlorides, potassium, calcium, in which the impurity $3 d$ metals content does not exceed the value as a percentage of $(1-4) \cdot 10^{-7}$. Due to the properties of highly pure magnesium compounds to the sorption of metal ions, it is possible to create reference samples of chemical elements for the needs of metrology. For example, to create MR phantoms to verify measurements and check the operation of magnetic resonance imaging (MRI) in medical institutions. Especially pure magnesium hydroxide can be used for instrumental methods of analytical chemistry (X-ray fluorescent, neutron-activation methods) when fabricating chemical references for testing laboratories.

Keywords: magnesium compounds, alkaline hydrolysis of magnesium chloride, magnesium hydroxide, sorption of metalions

\section{TECHNOLOGY FOR OBTAINING HIGH- PURE MAGNESIUM COMPOUNDS USING THE HYDROLYTIC PROCESSES OF SEDIMENTATION}

\author{
Mikhailsichov \\ PhD, Associate Professor* \\ Kostiantyn Boriak \\ Corresponding author \\ Doctor of Technical Sciences, Professor* \\ E-mail: kostya.boryak@gmail.com \\ Le onid Kolomiets \\ Doctor of Technical Sciences, Professor \\ Department of Standardization, Conformity \\ Assessment and Educational Measurements** \\ *Department of Metrology and Information and \\ Measuring Technology** \\ $* *$ State University of \\ Intelligent Technologies and Communications \\ Kuznechnastr., 1, Odessa, Ukraine, 65020
}

Received date 29.12.2021 Accepted date 08.02.2022 Published date 28.02.2022
How to Cite: Sichov, M., Boriak, K., Kolomiets, L. (2022). Technology for obtaining high-pure magnesium compounds using hydrolytic depositioning processes. Eastern-European Journal of Enterprise Technologies, 1 (6 (115)), 43-52. doi:https://doi.org/10.15587/1729-4061.2022.253544

\section{Introduction}

Magnesium and its compounds are among the most common on Earth. These compounds are in the form of land minerals: carbonates, magnesites, and serpentinites. There are also manifestations of the mineral brucite. However, most magnesium compounds exist in the form of solutions of its salts in the waters of the seas and oceans, salt lakes and estuary, or in the form of bischofite - a saturated solution of magnesium chloride [1]. The use of land minerals is quite difficult in the technological processes of their processing into target compounds - magnesium hydroxide and its oxide. The attention of scientists and technologists is attracted by the possibility of using natural solutions to obtain magnesium compounds from them, which are needed. Particular attention is paid to the technology of nanostructured magnesium hydroxide for the needs of the latest chemical technologies in organic chemistry, the extraction of compounds of valuable metals, in environmental and security means of meeting human needs.Studies into structure formation, the possibility of programming sediment processes are still relevant [2]. This is evidenced by the emergence of new research, technologies of the latest magnesium materials, expansion of production, increase in the volume of the production of magnesium compounds in Russia, China, USA[3].

Among the technologies for obtaining magnesium compounds, the most attractive are those that meet new areas of need for its highly pure and functional compounds. Increasing the requirements for electrochemical properties in the production of components of electronics for the aerospace industry in the world requires sufficiently clean reagents [4]. Methods of preparation of such reagents are quite complex. Therefore, there is a need to use new reagents that are simple, genetically related to the raw materials and the target 
product. The relevance of this study is associated with the development of new technology for obtaining sediment using the method of "Emerging reagent" and its subsequent application in the technology of obtaining highly pure magnesium compounds. Simplification and cheapening of the existing technology for obtaining highly pure magnesium compounds is relevant for many sectors of society.

\section{Literature review and problem statement}

Taking into consideration the importance of the technology of obtaining magnesium hydroxide, an analysis of the state of scientific and experimental studies was carried out on the chemical aspects of obtaining it from solutions of its salts (mainly magnesium chloride). Technologies for obtaining high-purity magnesium hydroxide and magnesium oxide are rapidly developing in China regarding the use of magnesium hydroxide with a nanostructure to extract terbium lanthanide from solutions of strategic importance. In Russia, where there are various raw materials sources of magnesium compounds, they pay great attention to their production [5]. Perfect technologies have been developed and large production facilities have been organized, which are described with a significant amount of information in publications. However, along with the existing descriptions of a number of technologies, there are no descriptions of chemical processes used to ensure the purity of reagents, types of such reagents and their features, and choice justification. Paper [6] reports existing technologies in Russia, where the production of magnesium products has a large volume and is in demand, but there are no data on the methods of filtration of magnesium hydroxide and research into the degree of purification of reagents, raw materials. It is not specified how the issues of obtaining high purity products and the peculiarities of filtration in technology are solved. The exception is data from [5], which indicates the use of the most accessible alkali, as a solution of lime (calcium hydroxide). However, it is known that the alkaline reagent calcium hydroxide also does not provide high-quality sediment of magnesium hydroxide, its purity. Fundamentally, it is impossible to obtain lime free from impurities, although most technologies are based on the use of lime as an alkaline reagent. There are needs for obtaining heat-resistant plastics and fire-resistant products from them when using magnesium hydroxide and its oxide in the form of structures with nanoscale particles [6]. At the same time, there are no requirements for the technology and its features for obtaining particles of hydroxide and magnesium oxide, the effect of their size for fillers in plastics with refractory properties.

It is indicated that the technology of nanostructured magnesium hydroxide is of great importance [7]. The properties of $\mathrm{MgO}$ and $\mathrm{Mg}(\mathrm{OH})_{2}$ nanostructured powders were studied in [8]. A greater advantage of nanostructured hydroxide is shown compared to that of a multilayer structure and with $\mathrm{MgO}$ properties. Methods of synthesis of products from nanostructured hydroxide are highlighted in work [9].The adsorption properties of the nanostructured $\mathrm{Mg}(\mathrm{OH})_{2}$ and $\mathrm{MgO}$ were discussed in [10]. Work [11] reports methods for obtaining the nanostructure and the structure of [Mg $]_{n}$ clusters. Study [12] provides information about modern research in China on the use of magnesium hydroxide with a nanostructure to extract terbium lanthanoid from solutions of strategic importance. However, there is no information on research methods, only a general description of the method of obtaining magnesium hydroxide from diluted solutions of sodium alkali chloride for composite materials is given. The attention of scientists and technologists is attracted by the possibility of using natural solutions of magnesium salts to obtain highly pure magnesium compounds for the pharmaceutical industry [13]. For society, this need has grown significantly, there are new, non-traditional medicines that have a multifunctional purpose in the context of the development of viral epidemics, so the experiments and production of highly pure raw materials for pharmaceuticals are of great importance.

High-purity magnesium hydroxide can serve as a material for sorption and sediment-matrix formation for other metal ions, which are determined by the analysis of substances and solutions. Thatcould increase the reliability of the results of X-ray fluorescent and atomic absorption tests [14]. It is shown that it is possible to create highly pure compounds for medicine (creation of MR phantoms for verification of measurements and verification of the work of magnetic resonance imaging scanners) [15].

In the production of magnesium hydroxide in alkaline precipitate from its saline natural solutions, there are two features. It is shown that the first of them is that magnesium hydroxide has a sufficiently high ability to sorption of ion forms of most 3-d metals [16]. Thatmakes it possible to get solutions sufficiently free from foreign compounds, primarily 3 -d metals [17] at a satisfactory sediment filtration rate. The use of adsorbents of an extraneous nature and composition requires the cost of their synthesis and restoration of properties [18]. The second feature of the sediment is associated with its structure, which is significantly watered and has the ability to deform water layers and environmental pressure and slows down filtration [19]. The low rate of filtration when the sediment of magnesium hydroxide is separated from the uterine fluid has always been the subject of separate studies and proposed methods of formation. To clean raw materials solutions, it is proposed to heat raw brine [20]. Partial deposition of magnesium hydroxide is known, which increases the filtration rate to $180 \mathrm{~kg} / \mathrm{m}^{2}$ per hour [21]. Increasing the value of alkalinity to pH1012 during deposition leads to a decrease in the rate of filtration of magnesium hydroxide sediment, so it is important to regulate such deposition and not to carry it out understoichiometric conditions.There are known methods to form the sediment of magnesium hydroxide under the conditions of using inactive alkaline reagents; the use of etching retur during deposition; the use of surfactants; heating the reaction volume; electrical deposition [22]. However such techniques to satisfy the filtration of magnesium hydroxide significantly complicate the entire technology, making it unprofitable. It is also known that the ability to sorption of foreign metals-ions with magnesium hydroxide is influenced by the state of the structure of hydroxide and the state of the forms of foreign metal-ions [23]. When an alkaline reagent is added to a magnesium solution, sediment is formed at a high rate, so foreign metal ions react mainly with the surface of magnesium hydroxide, without the participation of sorption-active centers of the sediment structure. It is important to ensure the conditions of uniform interaction of active centers in the structure of sediment with hydrolyzed forms of micro components. Work [15] earlier found that alkaline deposition of up to $5 \%$ of magnesium ions from the solution makes it possible to completely isolate impurity elements on hydroxide.An effective way to regulate the rate of formation of sediment of a uniform structure with effective centers is the 
method of homogeneous deposition [23]. Consideration of all technological methods for obtaining magnesium hydroxide shows that the method of homogeneous deposition using a reagent arising throughout the reaction volume is lacking in the descriptions of magnesium compound technologies and is first proposed in the current paper.

The advantages of homogeneous deposition are that the sediment reagent agent is formed evenly throughout the solution and gradually achieves the $\mathrm{pH}$ value necessary for deposition. Compared to ordinary, direct alkaline deposition yields large-crystalline sediments. An even more effective technique of uniform introduction of small concentrations of the sedimentary is deposition from a homogeneous solution (homogeneous deposition) or a method of emerging reagents. In this method, the sediment agent is formed as a result of hydrolysis of a specially introduced reagent in a raw material solution. This method is called homogeneous deposition by the method of emerging reagents. Even those substances that, in an ordinary precipitate, form amorphous sediments, can be obtained in the form of crystals during homogeneous deposition. This type of deposition according to the method of emerging reagents makes it possible to obtain crystalline sediments of magnesium hydroxide with satisfactory adsorption and filtration properties. This technology for the deposition of magnesium hydroxide from solutions has been proposed for the first time and has not been investigated by anyone. Therefore, it is important to confirm the declared theoretical foundations by experimental studies or refute them after receiving the results.

\section{The aim and objectives of the study}

The purpose of this study is to determine the processes of magnesium hydrolysis in highly concentrated solutions of its chloride. This would make it possible to obtain solutions of magnesium hydroxocomplexesas reagents for homogeneous deposition of magnesium hydroxide. Such sediment has a high filtration coefficient and satisfactory sorption properties, which are suitable for the technology of obtaining highly pure magnesium compounds.

To accomplish the aim, the following tasks have been set:

- to investigate the processes of alkaline hydrolysis of magnesium ions in a wide range of concentrations of its chloride and the conditions for the formation of solutions of magnesium hydroxocomplexes;

- toexplore the possibility of using solutions of magnesium hydroxocomplexes as a reagent in the method of homogeneous formation of its hydroxide;

- to investigate the peculiarities of sedimentation of magnesium hydroxide, its structure, the sorption and filtration properties of sediments;

- based on the results of the current research and their generalization to propose a simplified and cheaper scheme of technology for obtaining highly pure magnesium compounds and several alkali metals.

\section{The study materials and methods}

To tackle the set tasks, it is necessary to establish the composition and structure of hydrolyzed magnesium forms, to investigate the peculiarities of the process of sedimentation of its hydroxide by the method of the emerging reagent. Experiments were conducted with alkaline deposition of magnesium hydroxide from its chloride of varying degrees of concentration of $0.05-4.0 \mathrm{~mol} / \mathrm{dm}^{3}$. In this case, a solution of sodium hydroxide of a constant concentration of $0.2 \mathrm{~g} / \mathrm{dm}^{3}$ was used, which was added to the magnesium chloride solution.To study the processes of sedimentation, physical and chemical methods were used: solubility, conductometric and potentiometric titration, nephelometry, sedimentary volume, sedimentation analysis method. When determining the composition of sediments, the method of residual concentrations, the preparation and analytical method (a variant of the method of moisture sediment with an indifferent component) were also used.X-ray analysis of sediment samples was used to determine their composition and structure according to diffractogramsacquired from the diffractometer DRON0.5, radiation SI-K $\mathrm{K}_{\dot{\alpha}}$ with a Ni-filter, the identification was carried out by the radiographic database ASTM. The size of sediment crystals (primary particles and formed crystals) was estimated by the spread of X-ray diffraction peaks according to the Debye-Scherrer formula.

Infrared IR spectra were obtained using the Spekord-75 IR spectrometer. Samples were prepared by pressing tablets with dried at $150{ }^{\circ} \mathrm{C}$ compound $\mathrm{KBr}$,grade "chemically pure $3-4$ ", the spectra were recorded in the spectral region of $400-4000 \mathrm{~cm}^{-1}$.

A comprehensive thermal analysis was carried out on the derivatograph of the PauliqueErdey system, made by IOM (Hungary). We examined the structure of sediments and their size by optical microscopy methods at the electron microscope H-500 of Hitachi(Japan). The optical microscope MP-6 with an object micrometer was also used. A statistical analysis of the obtained photos was carried out, which was supplemented by data from the sedimentation analysis.

The physicochemical characteristics of the sediments were defined as the results of filtration of the suspension of magnesium hydroxide when diluted in a Bunsencupin the corresponding vacuum system. The filter factor was determined from the formula:

$$
Q=K_{f} \cdot S \cdot H / l \cdot t,
$$

where $Q$ is the volume of the filtrate, $\mathrm{cm}^{3}$;

$K_{f}$ is the filtration factor, $\mathrm{cm} / \mathrm{s}$;

$\mathrm{H}$ isthe liquefaction under the filter, $\mathrm{cm} \mathrm{H}_{2} \mathrm{O}$;

$l$ is the sediment thickness;

$t$ - the length of filtration, time.

Specific electrical conductivity was measured using the OR-201 conductometer. Potentiometric, pH-metric studies with the use of ion-selective electrodes were carried out at the device "pH-meter",brandpH-340 (Belarus). Photo-electro-colorimetric measurements were carried out at the devices SF-24 and KFC-3 (Russia).

The processing of graphical dependences of the properties of magnesium hydroxide sediment on supersaturation, in order to find empirical formulas, was carried out by an alignment method.

\section{Results of studying conditions for the production of magnesium hydroxide as an effective sorbent with different filtration properties}

\footnotetext{
5. 1. Investigating the hydrolysis of magnesium ions in the solutions of its chloride

To solve the specifiedtasks, experiments were conducted with alkaline deposition of magnesium hydrox-
} 
ide from its chloride of various degrees of concentration, $0.05-4.0 \mathrm{~mol} / \mathrm{dm}^{3}$; a solution of sodium hydroxide of a constant concentration of $0.2 \mathrm{~g} / \mathrm{dm}^{3}$ was used. For magnesium chloride concentrations $\left(0.1-0.5 \mathrm{~g} / \mathrm{dm}^{3}\right)$, the existence of two main types of sediments at $\mathrm{pH}=8.22-9.86$ was established. It was found that the first type of sediment, at the beginning of the deposition, with the product of solubility $\mathrm{PS}=(2,41-2,64) \cdot 10^{-10}$, corresponds to the known labile (active) form of magnesium hydroxide with $\mathrm{PS}=3.47 \cdot 10^{-10}$. The second type of sediment (at the end of deposition) with $\mathrm{PS}=(1,15-1,54) \cdot 10^{-11}$ most corresponds to the value for the crystallized form of hydroxide with $\mathrm{PS}=1,48 \cdot 10^{-10}[24]$. The values of the products of solubility of sediments calculated according to the results of experiments were compared with those reported in chemical studies [25,26]. Such results held for all concentrations of magnesium chloride in our experiments. It was found (there are no other data in the literature) that the active magnesium hydroxide has the ability to react with magnesium chloride and pass into the solution (without the formation of a solid phase).

This ability to dissolve the labile form of magnesium hydroxide is noticeable already at a concentration of magnesium chloride of $1 \mathrm{~g}$-ion $/ \mathrm{dm}^{3}$ and increases with an increase in the initial concentration of magnesium chloride (Fig. 1).

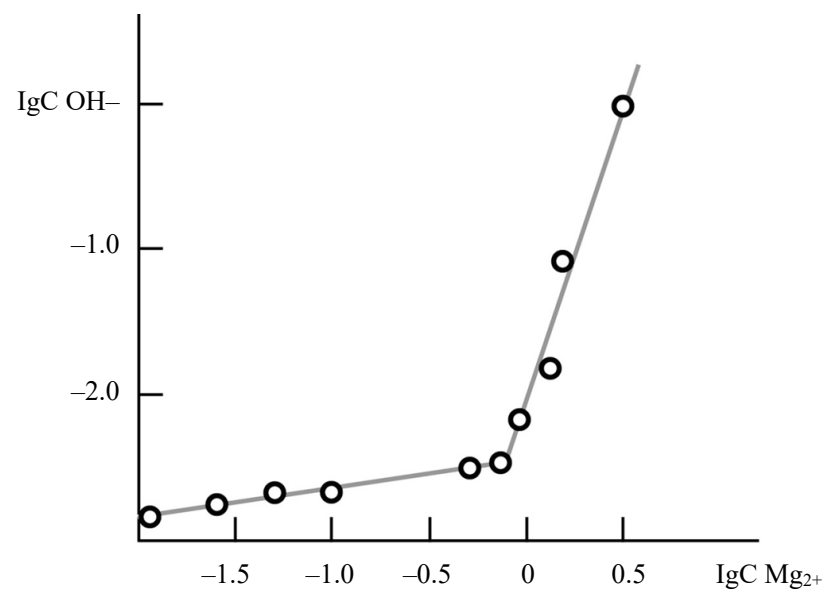

Fig. 1. Dependence of the alkalinity of $\mathrm{MgCl}_{2}$ solutions on their concentration when magnesium hydroxide is deposited

In this case, the concentrations of magnesium chloride of 1.0-4.75 g-ion $/ \mathrm{dm}^{3}$ make it possible, after dissolving the active hydroxide, to form it with alkali again until the dissolution process stops. This formation of metastable solutions indicates the interaction of concentrated solutions of magnesium chloride and the original labile form of magnesium hydroxide with the formation of magnesium hydroxocomplexes. The formation of such complexes corresponds to the theory of "core+link" [27]. The core is magnesium chloride (oxychloride), and the link is magnesium hydroxide of the labile (active) form, according to the following scheme:

$$
\begin{aligned}
& \mathrm{MgCl}_{2}+2 \mathrm{OH}^{-} \rightarrow(\text { active }) \mathrm{Mg}(\mathrm{OH})_{2}+ \\
& +\mathrm{MgCl}_{2} \rightarrow 2 \mathrm{MgOHCl}\left[\mathrm{Mg}_{2}(\mathrm{OH})_{2}\right] \mathrm{Cl}_{2}, \\
& {\left[\mathrm{Mg}_{2}(\mathrm{OH})_{2}\right] \mathrm{Cl}_{2}+} \\
& + \text { (active }) . \mathrm{Mg}(\mathrm{OH})_{2} \rightarrow\left[\mathrm{Mg}_{3}(\mathrm{OH})_{4}\right] \mathrm{Cl}_{2},
\end{aligned}
$$

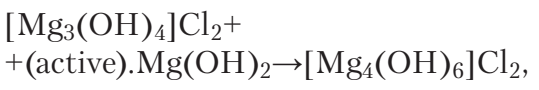

$$
\begin{aligned}
& {\left[\mathrm{Mg}_{\mathrm{n}}(\mathrm{OH})_{2 \mathrm{n}-2}\right] \mathrm{Cl}_{2}+\mathrm{Mg}(\mathrm{OH})_{2} \rightarrow} \\
& \rightarrow\left[\mathrm{Mg}_{\mathrm{n}+1}(\mathrm{OH})_{2 \mathrm{n}-2}\right] \mathrm{Cl}_{2}\left(\left[\mathrm{Mg}_{\mathrm{n}}(\mathrm{OH})_{2 \mathrm{n}-2}\right] \mathrm{Cl}_{2}\right)
\end{aligned}
$$

According to the provisions of the theory "core+link", it was found that magnesium ions in solutions can exist in the form of hydroxocomplexes of the general formula $\left[\mathrm{Mg}_{\mathrm{n}}(\mathrm{OH})_{2 \mathrm{n}-2},\right]^{2+}$, where $n=1,2,3, \ldots$, corresponding to the composition of magnesium compounds, which eventually fall out of such metastable solutions of magnesium complexes. The comparison of the composition of such sediments shows their genetic correspondence to the composition of hydroxocomplexes of the solution.

\section{2. Studyingthe sedimentation of magnesium hy-} droxide by the method of "Emerging reagent"

Further studies of the homogeneous formation of magnesium hydroxide sediments according to the method of "Emerging reagent" showed that in the case of dilution of concentrated solutions of magnesium chloride containing hydroxocomplexes, magnesium hydroxide sediments occur according to the hydrolysis equation when diluting hydroxocomplexes solutions according to the following scheme:

$$
\left[\mathrm{Mg}_{\mathrm{n}}(\mathrm{OH})_{2 \mathrm{n}-2}\right]^{2+}+2 \mathrm{H}_{2} \mathrm{O} \rightarrow \mathrm{nMg}(\mathrm{OH})_{2}+2 \mathrm{H}^{+} .
$$

These sediments have several specific properties and compositions depending on the time of their formation; the process of sediment formation takes place in three stages (Fig. 2).

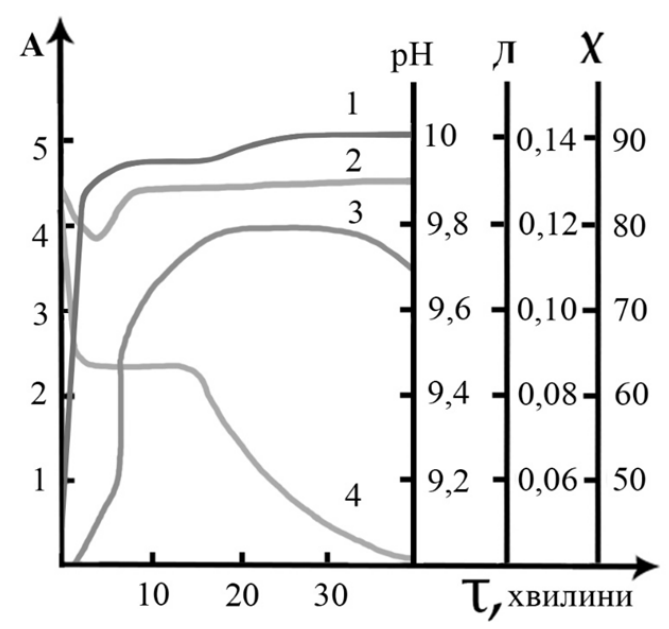

Fig. 2. Formation of magnesium hydroxide sediment during dilution of alkaline solutions $\mathrm{MgCl}_{2}$ from 4 to $0.5 \mathrm{~mol} / \mathrm{dm}^{3}$, $\tau$ is the sediment formation time, min; 1 - the amount of $\mathrm{Mg}^{2+}$ in the sediment (A), \% of the initial amount; 2 - electrical conductivity of the reaction medium $(\chi), \mathrm{Ohm}^{-1} \cdot \mathrm{cm}^{-1} \cdot 10^{-3}$; 3 - optical density (D); $4-\mathrm{pH}$ environment

We studied sediments at three main stages of formation, their composition, and properties based on experimental data. Such data were obtained by $\mathrm{pH}$-metric methods, electrical conductivity, optical properties (nephelometry) of the reaction medium. In addition, in the experiments, we used 
instrumental methods of Infrared-spectroscopy, including deuteroanalogues(Fig. 3), X-ray structure and X-ray analysis, thermography (Fig. 4), and electron microscopy (Fig. 5).

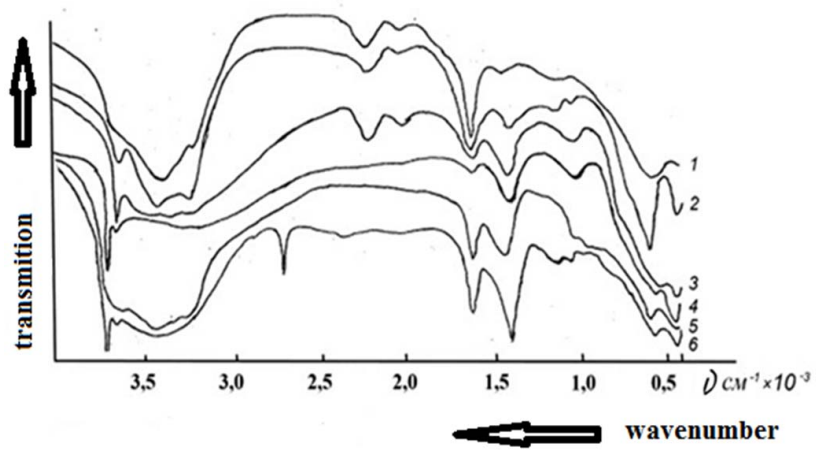

Fig. 3. Infrared spectra of magnesium hydroxide sediment phases: 1, 2 - embryos; 3 - primary particles; 4 -crystals of magnesium hydroxide; 5,6 - deuterated samples of embryos and crystals; $v$ - wavenumber

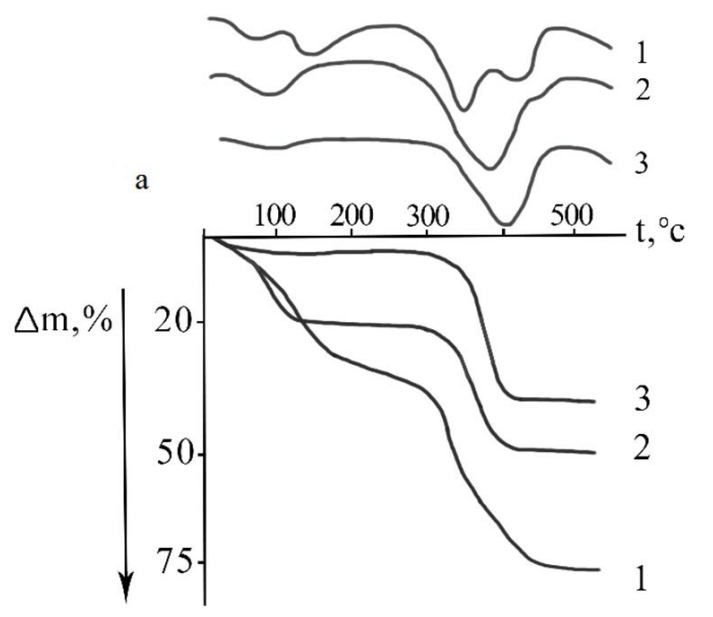

6

Fig. 4. Thermographic analysis of sediment samples at different stages of formation: $a$-change in the temperature of samples; $b$-change in the mass of samples; $\Delta \mathrm{m}, \%$ - weight loss of samples; 1 - embryos;

2 - primary particles; 3 - crystals
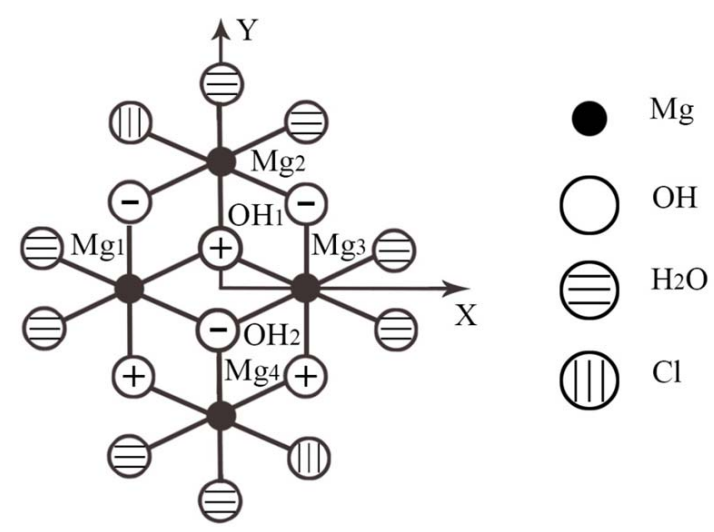

Fig. 5. The cluster structure of magnesium hydroxide embryos in dilution conditions
Infrared spectra (Fig. 3) allow us to draw conclusions about the composition and structure of solid phases of magnesium hydroxide when diluting alkaline solutions of its chloride. For the embryo phase, fluctuations in water molecules include a number of absorption bands at $3400-v(\mathrm{OH})\left(\mathrm{H}_{2} \mathrm{O}\right)$, $1620-1650-\delta\left(\mathrm{H}_{2} \mathrm{O}\right), 545-560 \mathrm{~cm}^{-1}-\rho\left(\mathrm{H}_{2} \mathrm{O}\right)$. Absorption bands in the region of $1020-1220 \mathrm{~cm}^{-1}$ indicate deformation oscillation of coordinated $\mathrm{Mg}-\mathrm{OH}^{+}$hydroxogroups. Water molecules coordinated with $\mathrm{OH}$-groups around magnesium atoms give a wide intense band at $3400 \mathrm{~cm}^{-1}$. Our calculation,based on the method from [28], for wavenumbers at $3420 \mathrm{~cm}^{-1}$ and $3250 \mathrm{~cm}^{-1}$ give the value of hydrogen bond energy $\mathrm{E}_{\mathrm{H}(1)}=19.2$ and $\mathrm{E}_{\mathrm{H}(2)}=9.42 \mathrm{~kJ} / \mathrm{mol}$.

These values differ from the hydrogen bond energy value for $\left[\mathrm{Mg}(\mathrm{OH})_{2}\right]_{n}-8.82 \mathrm{~kJ} / \mathrm{mol}$, indicating the proton-donor nature of the embryos compared to the crystallized form of magnesium hydroxide. The absence of a band of valence oscillations of free hydroxidegroups at $3690 \mathrm{~cm}^{-1}$ indicates the absence of a crystalline sediment structure consisting of $\left[\mathrm{Mg}(\mathrm{OH})_{2}\right]_{n}$.

The embryos are X-ray amorphous, unlike crystals, their thermographic analysis reveals (Fig. 4) that the release of structural water at $75-90{ }^{\circ} \mathrm{C}, \mathrm{E}_{\text {active }}=9.42 \mathrm{~kJ} / \mathrm{mol}$ at $100-140{ }^{\circ} \mathrm{C}, \mathrm{E}_{\text {active }}=19.6 \mathrm{~kJ} / \mathrm{mol}$. The stage of formation of primary particles of the second stage proceeds up to $100{ }^{\circ} \mathrm{C}$ (activation energy, $28.5 \mathrm{~kJ} / \mathrm{mol}$, corresponding to $\mathrm{E}_{\mathrm{H}(1)}+\mathrm{E}_{\mathrm{H}(2)}$ [28]. Thermal decomposition of crystals from the third stage of sediment proceeds at $412-420{ }^{\circ} \mathrm{C}$, when decomposing crystals from the third stage of sediment there is no dehydration. The decomposition of crystals during dilution is characterized by the activation energy of $113-120 \mathrm{~kJ} / \mathrm{mol}$, as opposed to the decomposition of sediment from fragments of surface or linear groups, $\mathrm{E}=78.3-87 \mathrm{~kJ} / \mathrm{mol}$, which indicates a perfect structure, grown during dilution [29].

The composition of the embryos (phase 1 particles) corresponds to $\mathrm{Mg}_{4}(\mathrm{OH})_{6} \mathrm{Cl}_{2} \cdot 8 \mathrm{H}_{2} \mathrm{O}$ with water molecules that give the embryos an active hydrogen bond and which are coordinated together with $\mathrm{OH}^{-}$groups (Fig. 5). The structure of the embryos and their composition together with the obtained data can be imagined based on the structure of the lattice of magnesium hydroxide [29]. In the layers of the crystal lattice [30], a single isolated fragment is a cluster of composition $\left[\mathrm{Mg}_{4}(\mathrm{OH})_{16}\right]^{8-}$, which is the coordination octahedron of hydroxide ions around each metal atom.

Such an octahedral structure persists in embryos, the composition of which, according to chemical, spectroscopic, and thermographic analyses, indicates the presence of $\mathrm{OH}$ groups and coordinated water molecules around magnesium atoms. The embryo formula (phase 1 particles) corresponds to $\mathrm{Mg}_{4}(\mathrm{OH})_{6} \mathrm{Cl}_{2} \cdot 8 \mathrm{H}_{2} \mathrm{O}$ with coordinated $\mathrm{OH}$ groups and water molecules that give the embryos an active hydrogen bond. The embryos have the structure and composition of $\mathrm{Mg}_{4}(\mathrm{OH})_{6} \mathrm{Cl}_{2} \cdot 8 \mathrm{H}_{2} \mathrm{O}$ with a critical embryo diameter of $2-3 \mathrm{~nm}$, which corresponds to the average diameter of the formation of 4 magnesium atoms, 6 hydroxide groups, and 8 water molecules [31].

At the first stage of sediment formation, the solution is turbid - the formation of embryonal sediment particles and a decrease in the $\mathrm{pH}$ of the solution. Subsequently, at the second stage, the transition of embryo particles into primary particles proceedsthrough their growth and polymerization to $(30-60) \mathrm{nm}$ at a constant $\mathrm{pH}$. At the third, final stage, the formation of sediment with the participation of particles 
of the second stage and mononuclear hydroxocomplexes of magnesium $\mathrm{MgOH}^{+}$bond continues. The formation of a crystalized stable structure by its oriented build-up from primary particles takes place after the transition of all embryo particles into primary particles. Sedimentation ends with the coalescence of all primary particles into a stable crystalline structure of magnesium hydroxide with a crystal size of 1000-4000 nm. Such features of the formation of magnesium hydroxide sediment when diluting concentrated solutions of magnesium chloride, which contain alkaline magnesium complexes, are also evidenced by the data on the negative charge of embryo particles of sediment by the value of the suspension effect, $\Delta \mathrm{pH}$ (Fig. 6).

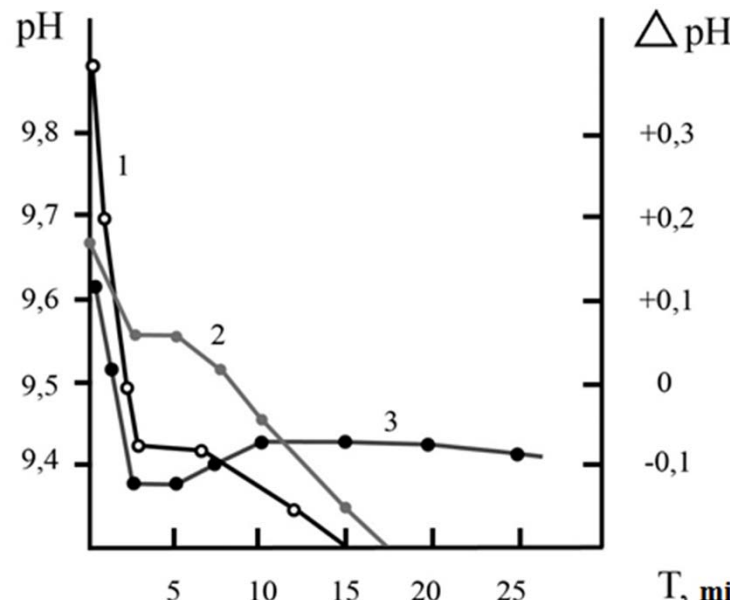

Fig.6. Value of the medium $\mathrm{pH}$ in the formation of $\mathrm{Mg}(\mathrm{OH})_{2}$ when diluting alkaline solutions $\mathrm{MgCl}_{2}: 1-\mathrm{pH}$ of the uterine solution; $2-$ suspension $\mathrm{pH} ; 3-\Delta \mathrm{pH}=\mathrm{pH}_{\text {iner.sol. }}-\mathrm{pH}_{\text {susp. }}$.

It is established that the formation of magnesium hydroxide sediment when concentrated solutions of magnesium chloride are diluted (more than $1.0 \mathrm{~g}-\mathrm{mol} / \mathrm{dm}^{3}$ ) takes place in a kinetic mode, with the order of reaction at the first stage $n_{1}=4$; at the stage of crystallization, the reaction order is $n_{2}=20$ [32]. The crystallization process is limited to $S=a_{\mathrm{Mg}}^{2+} a_{\mathrm{OH}}{ }^{-} / \mathrm{DR} \mathrm{Mg}(\mathrm{OH})_{2}$ supersaturation, where $a_{\mathrm{Mg}}^{2+}$ is an active concentration of magnesium ions in the solution after dilution, which is determined using an ion-selective electrode, $\mathrm{a}_{\mathrm{OH}}{ }^{-}$is the active concentration of hydroxideions in the solution determined by the potentiometric method.

It was established that sediment with crystals of size $1000-4000 \mathrm{~nm}$ and, accordingly, with the filtration rate $K_{f}=8 \cdot 10^{-3} \mathrm{~m} / \mathrm{h}$ during the separation of the solid phase from the solution, can be obtained by observing the conditions of dilution of alkaline solutions of magnesium chloride.

The results of our studies testify that the most important indicator is the amount of supersaturation at the values of $S \leq 20$ (Fig. 7), which makes it possible to obtain large-crystalline sediment of the collector, which is satisfactory for rapid filtration and separation of the solution. The main filtration rate indicator, $K_{\phi}=8 \cdot 10^{-3} \mathrm{~m} / \mathrm{h}$, in this case, compares favorably with the known values for magnesium hydroxide deposited with alkali, which have an average value of $K_{f}=8 \cdot 10^{-9} \mathrm{~m} / \mathrm{h}$.

The size of prismatic crystals of magnesium hydroxide sediment is $1000-4000 \mathrm{~nm}$ (Fig. 7), and the size of sediment crystals in a normal alkaline deposition is $42-75 \mathrm{~nm}$. The proposed method for studying the process of sedimentation of magnesium hydroxide is a method of emerging reagents, owing to which it is possible to obtain a large-crystalline precipitate. This method does not require the creation of any special conditions for it.

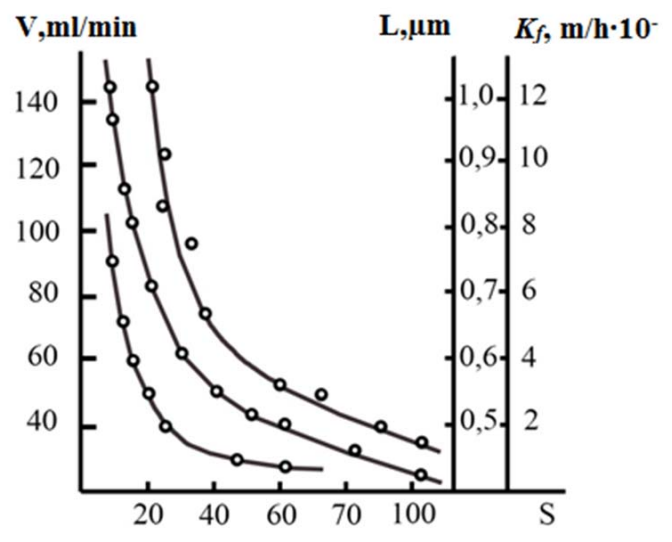

Fig. 7. Dependence of the properties of magnesium hydroxide sediment on the value of supersaturation, $\mathrm{dm}^{3}$ : 1 - the size of sediment crystals $(/, \mu \mathrm{m})$; 2 - specific filtration rate $(V, \mathrm{ml} / \mathrm{min})$;

3 - filtration factor $\left(K_{f}, \mathrm{~m} / \mathrm{h} \cdot 10^{-3}\right), S$ when diluted from 2.0 to $0.1 \mathrm{~mol} / \mathrm{dm}^{3}$
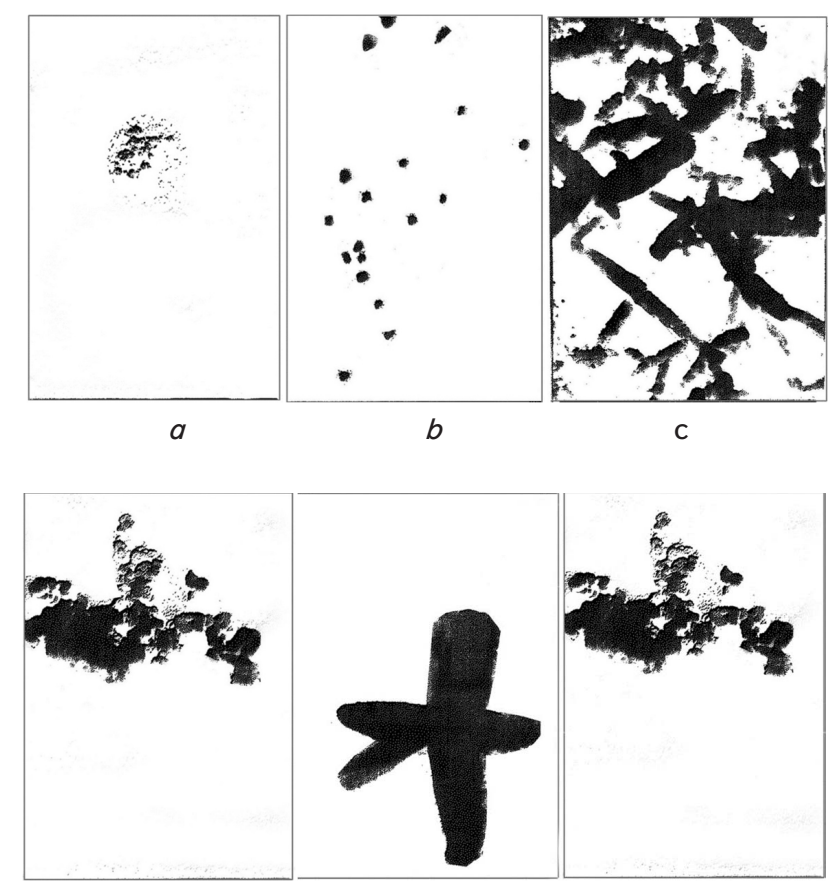

d

e

$f$

Fig. 8. Micrographs of magnesium hydroxide sediment particles at different stages of deposition under dilution conditions: $a$ - embryos; $b$ - initial particles;

$c, d, e-$ crystals; $f$-crystals of alkaline deposition. Electron microscope Hitachi H-500, coal replicas. Magnification, 85,000 times

Mathematical processing by equalization [32] of graphic experimental data (Fig. 8) has made it possible to express the dependence of the properties of the sediment on the value of 
the supersaturation, $\mathrm{S}$, when diluted, in the form of empirical formulas:

$$
l=60,3 / S^{1,25},
$$

where $l$ is the sediment crystal size, $\mathrm{mm}$;

$$
V=620 / S^{0,684}
$$

where $V$ is the specific filtration rate, $\mathrm{ml} / \mathrm{min}$;

$$
K_{f}=0,16 / S^{1,4}
$$

Where $K_{f}$ is the filtration coefficient, $\mathrm{m} / \mathrm{g} ; S$ is the supersaturation value.

\section{3. Investigating conditions for obtaining highly} pure magnesium compounds

Regarding the influence of the properties of sediment particles before the removal of micro quantities of admixture metal ions from the solution, it was established that the greatest ability to sorption is demonstrated by the particles of sediment of the first stage during the formation of the embryonic phase [12]. The embryos have a polymeric structure of $\mathrm{Mg}_{4}(\mathrm{OH})_{6} \mathrm{Cl}_{2} \cdot 6 \mathrm{H}_{2} \mathrm{O}$ clusters (Fig. 5), which contain active hydroxide groups and water molecules, have hydrogen bonds, and are capable of chemical interaction (sorption) with forms of impurity metals hydrolyzed at $\mathrm{pH} \sim 9.0$.

Such interaction is basic and irreversible with further sedimentation and crystallization. Similar processes of interaction of micro quantities of hydrolyzed ionic forms of metals with negatively charged surfaces of hydroxides are known from studies reported in [16].

The degree of purification of magnesium chloride solutions depends both on the value of the original alkaline module $\dot{\alpha}=[\mathrm{OH}] /\left[\mathrm{Mg}^{2+}\right]$, and the final, after dilution, concentration of $\mathrm{MgCl}_{2}$ solution (Tables 1,2).

Table 1

\begin{tabular}{|c|c|c|c|c|c|c|c|}
\hline \multirow{3}{*}{ Type } & \multicolumn{7}{|c|}{ The content of impurities, wt. \% (in terms of $\mathrm{MgCl}_{2}$ ) } \\
\hline & \multicolumn{3}{|c|}{$\begin{array}{c}{\left[\mathrm{OH}^{-}\right] /\left[\mathrm{Mg}^{2+}\right] \text { in the }} \\
\text { starting solution }\end{array}$} & \multicolumn{4}{|c|}{$\begin{array}{c}{\left[\mathrm{MgCl}_{2}\right] \text { after dilution }{ }^{* *},} \\
\mathrm{~mol} / \mathrm{dm}^{3}\end{array}$} \\
\hline & 0.02 & 0.05 & 0.10 & 3.0 & 2.0 & 1.0 & 0.5 \\
\hline $\mathrm{Fe}$ & $5 \cdot 10^{-5}$ & $1 \cdot 10^{-6}$ & $3 \cdot 10^{-7}$ & $8 \cdot 10^{-5}$ & $2 \cdot 10^{-5}$ & $5 \cdot 10^{-7}$ & $1 \cdot 10^{-7}$ \\
\hline $\mathrm{Mn}$ & $3 \cdot 10^{-5}$ & $5 \cdot 10^{-6}$ & $1 \cdot 10^{-6}$ & $5 \cdot 10^{-4}$ & $3 \cdot 10^{-5}$ & $1 \cdot 10^{-6}$ & $6 \cdot 10^{-7}$ \\
\hline $\mathrm{Cu}$ & $1 \cdot 10^{-5}$ & $7 \cdot 10^{-6}$ & $1 \cdot 10^{-6}$ & $1 \cdot 10^{-4}$ & $2 \cdot 10^{-5}$ & $1 \cdot 10^{-6}$ & $2 \cdot 10^{-7}$ \\
\hline $\mathrm{Ni}$ & $6 \cdot 10^{-5}$ & $5 \cdot 10^{-6}$ & $1 \cdot 10^{-7}$ & $1 \cdot 10^{-4}$ & $2 \cdot 10^{-6}$ & $8 \cdot 10^{-7}$ & $2 \cdot 10^{-7}$ \\
\hline Co & $1 \cdot 10^{-5}$ & $2 \cdot 10^{-6}$ & $4 \cdot 10^{-7}$ & $8 \cdot 10^{-4}$ & $4 \cdot 10^{-5}$ & $1 \cdot 10^{-6}$ & $3 \cdot 10^{-7}$ \\
\hline $\mathrm{Cr}$ & $2 \cdot 10^{-5}$ & $7 \cdot 10^{-6}$ & $1 \cdot 10^{-6}$ & $1 \cdot 10^{-4}$ & $2 \cdot 10^{5}$ & $6 \cdot 10^{-6}$ & $4 \cdot 10^{-7}$ \\
\hline $\mathrm{V}$ & $1 \cdot 10^{-5}$ & $1 \cdot 10^{-5}$ & $2 \cdot 10^{-6}$ & $1 \cdot 10^{-4}$ & $7 \cdot 10^{-5}$ & $1 \cdot 10^{-5}$ & $2 \cdot 10^{-6}$ \\
\hline $\mathrm{B}$ & $5 \cdot 10^{-3}$ & $6 \cdot 10^{-5}$ & $6 \cdot 10^{-7}$ & $1 \cdot 10^{-2}$ & $3 \cdot 10^{-3}$ & $2 \cdot 10^{-5}$ & $1 \cdot 10^{-6}$ \\
\hline $\mathrm{Ca}$ & $1 \cdot 10^{-3}$ & $2 \cdot 10^{-4}$ & $7 \cdot 10^{-6}$ & $5 \cdot 10^{-3}$ & $8 \cdot 10^{-4}$ & $1 \cdot 10^{-4}$ & $1 \cdot 10^{-5}$ \\
\hline $\mathrm{S}$ & $1 \cdot 10^{-3}$ & $6 \cdot 10^{-4}$ & $3 \cdot 10^{-6}$ & $2 \cdot 10^{-3}$ & $6 \cdot 10^{-4}$ & $3 \cdot 10^{-4}$ & $5 \cdot 10^{-6}$ \\
\hline
\end{tabular}

Dependence of $\mathrm{MgCl}_{2}$ solution purity on the conditions of hydrolysis

Note: * $-\mathrm{MgCl}_{2}$ concentration after dilution was $0.5 \mathrm{~mol} / \mathrm{dm}^{3}$;

** - the $\left[\mathrm{OH}^{-}\right] /\left[\mathrm{Mg}^{2+}\right]$ ratio in the original solution was 0.08

These values determine the composition and concentration of magnesium hydroxocomplexes and their interaction during hydrolysis in the process of diluting the $\mathrm{MgCl}_{2}$ solution (Table 1), which, as a result, determines the speed of the crystal building process and the properties of magnesium hydroxide sediment.

Table 2

\begin{tabular}{|c|c|c|c|c|c|c|}
\hline \multirow{3}{*}{$\begin{array}{l}\text { Micro } \\
\text { impuri- } \\
\text { ty type }\end{array}$} & \multicolumn{6}{|c|}{$\begin{array}{l}\text { The content of impurities, wt. \% (in terms of } \\
\qquad \mathrm{MgCl}_{2} \text { and } \mathrm{MgO} \text { ) }\end{array}$} \\
\hline & \multicolumn{3}{|c|}{$\mathrm{MgCl}_{2} *$} & \multicolumn{3}{|c|}{$\mathrm{MgO}^{* *}$} \\
\hline & $\begin{array}{l}\text { Crude } \\
\text { com- } \\
\text { pound }\end{array}$ & $\begin{array}{l}\text { Puri- } \\
\text { fied } \\
\text { com- } \\
\text { pound }\end{array}$ & $\begin{array}{l}\text { Degree } \\
\text { of puri- } \\
\text { fication }\end{array}$ & $\begin{array}{l}\text { Crude } \\
\text { com- } \\
\text { pound }\end{array}$ & $\begin{array}{c}\text { Puri- } \\
\text { fied } \\
\text { com- } \\
\text { pound }\end{array}$ & $\begin{array}{l}\text { Degree } \\
\text { of puri- } \\
\text { fication }\end{array}$ \\
\hline $\mathrm{Fe}$ & $2 \cdot 10^{-4}$ & $1 \cdot 10^{-7}$ & $2 \cdot 10^{3}$ & $5 \cdot 10^{-4}$ & $5 \cdot 10^{-7}$ & $1 \cdot 10^{3}$ \\
\hline $\mathrm{Mn}$ & $2 \cdot 10^{-3}$ & $6 \cdot 10^{-7}$ & $3 \cdot 10^{3}$ & $5 \cdot 10^{-3}$ & $1 \cdot 10^{-6}$ & $5 \cdot 10^{3}$ \\
\hline $\mathrm{Cu}$ & $5 \cdot 10^{-4}$ & $2 \cdot 10^{-7}$ & $3 \cdot 10^{3}$ & $1 \cdot 10^{-3}$ & $1 \cdot 10^{-6}$ & $1 \cdot 10^{3}$ \\
\hline $\mathrm{Ni}$ & $3 \cdot 10^{-4}$ & $2 \cdot 10^{-7}$ & $2 \cdot 10^{3}$ & $7 \cdot 10^{-4}$ & $2 \cdot 10^{-7}$ & $3 \cdot 10^{3}$ \\
\hline $\mathrm{Co}$ & $1 \cdot 10^{-3}$ & $3 \cdot 10^{-7}$ & $3 \cdot 10^{3}$ & $2 \cdot 10^{-3}$ & $5 \cdot 10^{-7}$ & $4 \cdot 10^{3}$ \\
\hline $\mathrm{Cr}$ & $3 \cdot 10^{-3}$ & $4 \cdot 10^{-7}$ & $7 \cdot 10^{3}$ & $7 \cdot 10^{-3}$ & $1 \cdot 10^{-6}$ & $7 \cdot 10^{3}$ \\
\hline $\mathrm{V}$ & $2 \cdot 10^{-4}$ & $2 \cdot 10^{-6}$ & $1 \cdot 10^{2}$ & $5 \cdot 10^{-4}$ & $1 \cdot 10^{-6}$ & $5 \cdot 10^{2}$ \\
\hline $\mathrm{B}$ & $2 \cdot 10^{-2}$ & $1 \cdot 10^{-6}$ & $2 \cdot 10^{4}$ & $5 \cdot 10^{-2}$ & $1 \cdot 10^{-6}$ & $5 \cdot 10^{4}$ \\
\hline $\mathrm{Ca}$ & $1 \cdot 10^{-2}$ & $1 \cdot 10^{-5}$ & $1 \cdot 10^{3}$ & $1 \cdot 10^{-2}$ & $1 \cdot 10^{-5}$ & $1 \cdot 10^{3}$ \\
\hline $\mathrm{S}$ & $2 \cdot 10^{-3}$ & $5 \cdot 10^{-6}$ & $4 \cdot 10^{2}$ & $5 \cdot 10^{-3}$ & $1 \cdot 10^{-5}$ & $5 \cdot 10^{2}$ \\
\hline
\end{tabular}

Dependence of $\mathrm{MgCl}_{2}$ and $\mathrm{Mg}$ Opurity under optimal cleaning conditions

Note: * $-\mathrm{MgCl}_{2}$ concentration after dilution was $0.5 \mathrm{~mol} / \mathrm{dm}^{3}$; ** - the $\left[\mathrm{OH}^{-}\right] /\left[\mathrm{Mg}^{2+}\right]$ ratioin the original solution was 0.08

The data in Table 2 demonstrate that when depositing $5-10 \%$ of the original amount of magnesium when diluted to $0.5 \mathrm{~mol} / \mathrm{dm}^{3}$, a high degree of purification of $\mathrm{MgCl}_{2}$ solution from impurities and $\mathrm{MgO}$ from such solution is achieved.

5.4. Schemes of technologies for obtaining highly pure compounds of magnesium and alkali metals

Alkaline polycondensation of magnesium ions in concentrated solutions of its chloride followed by dilution is a universal technique both for obtaining highly pure magnesium compounds in (Fig. 9) and for the possible purification of a number of salts $-\mathrm{NaCl}, \mathrm{KCl}, \mathrm{CaCl}_{2}$ in pharmacy and medicine (Fig. 10).

Such technologies do not require complex equipment and special procedures and can simply be mastered on the existing raw material base of a number ofgalurgical enterprisesin Ukraine. As for waste, it can also be used. The main one magnesium hydroxide, as a collector of impurities of metal compounds in the given scheme, contains (wt\%) (in terms of $\mathrm{MgO}): \mathrm{Fe}-4 \cdot 10^{-3}, \mathrm{Mn}-4 \cdot 10^{-2}, \mathrm{Cu}-1 \cdot 10^{-2}, \mathrm{Ni}-6 \cdot 10^{-3}$, $\mathrm{Co}-2 \cdot 10^{-2}, \mathrm{Cr}-6 \cdot 10^{-2}, \mathrm{~V}-4 \cdot 10^{-2}, \mathrm{~B}-4 \cdot 10^{-1}, \mathrm{Ca}-4 \cdot 10^{-2}, \mathrm{~S}-$ $3 \cdot 10^{-2}$. In each cleaning cycle, this collector is removed from the process and can be used for appropriate needs - the production of heat-resistant ceramics, heat-insulating materials, transformer steel coating, etc. [1,3]. The purified target solutions of salts can be repeatedly treated to an ultra-high degree of purity in accordance with the specific requirements and needs of the latest equipment in its production.Highly pure magnesium hydroxide can be used to concentrate metal ions and radionuclides on such a highly pure collector for chemical analyses regarding their contents. Sorption properties and satisfactory filtration rate are suitable for cleaning natural and technical solutions. The concentration of scattered elements, especially lanthanoids, expands their raw materials for the needs of the latest technology. 


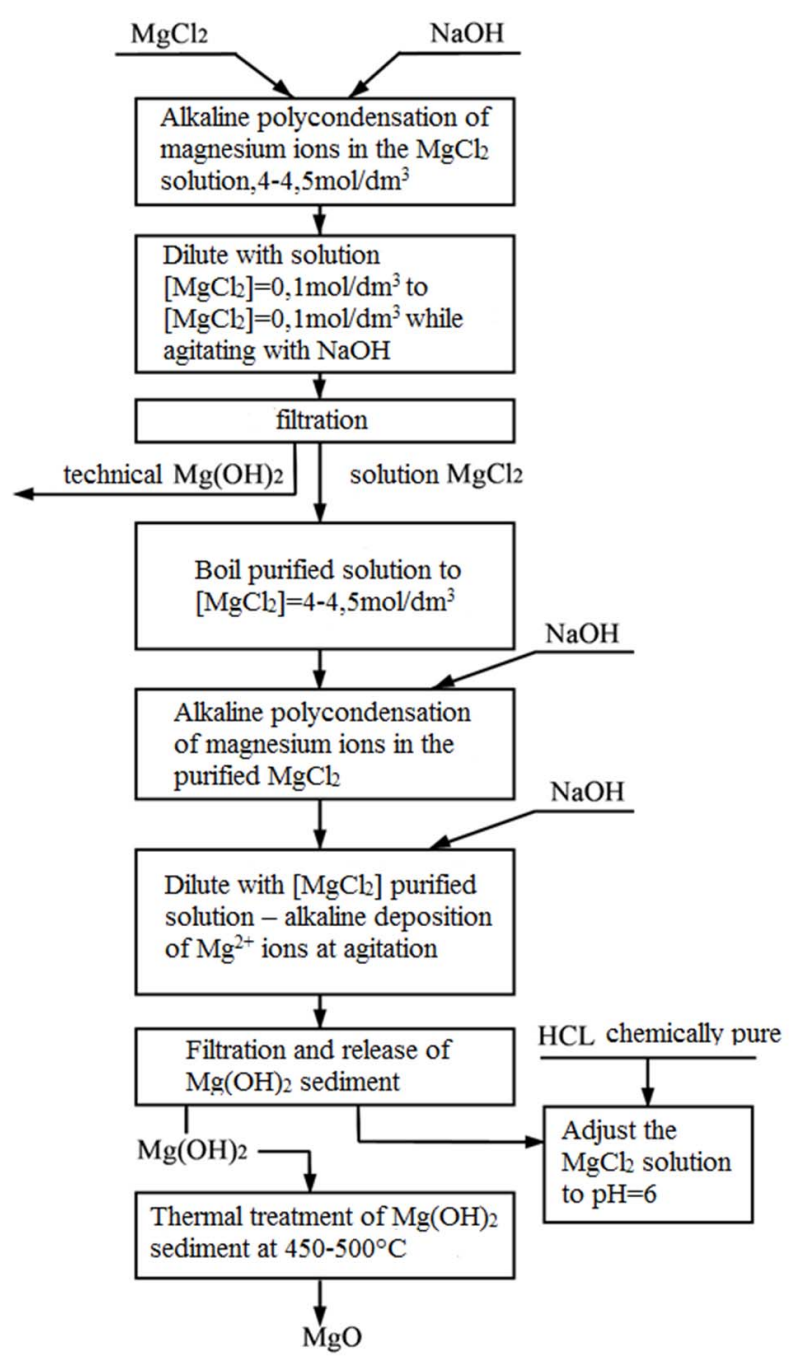

Fig. 9. Scheme for obtaining highly pure compounds $\mathrm{MgCl}_{2}$ and $\mathrm{MgO}$

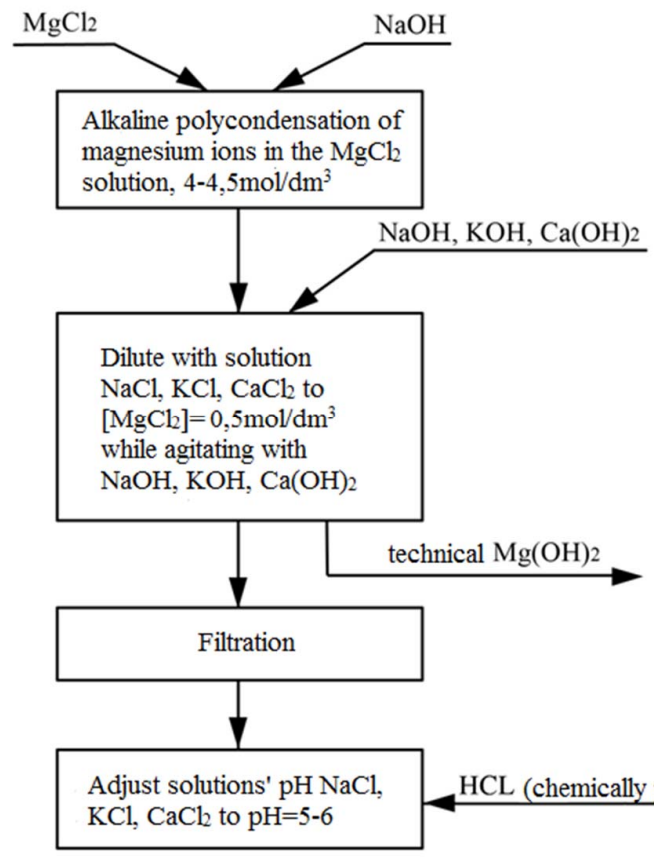

Fig. 10. Scheme for obtaining solutions $\mathrm{NaCl}, \mathrm{KCl}, \mathrm{CaCl}_{2}$, pharmacopeial purity
Variants of technological schemes for obtaining highly pure magnesium compounds, as well as salts of alkali metals (Figs. 9,10) based on the studied hydrolytic processes involving magnesium chloride and alkalis have been proposed.

\section{Discussion of results of studying the hydroxide sediment processes}

Our experimental results of the formation of magnesium hydroxide sediment by homogeneous deposition have confirmed the possibility and economic attractiveness of such technology for obtaining highly pure compounds of magnesium and alkali metals. The achieved values of the filtration coefficient exceed known ones from other studies by $1 \cdot 10^{6}$, and the degree of purification of target products from impurities of $3-\mathrm{d}$ metals reaches $(1-4) \cdot 10^{4}$ times. The experiments involving magnesium hydrolysis processes have shown the possibility of obtaining and applying a solution of hydrolyzed forms. Applying such a solution has shown that it is suitable for the method of emerging reagents in homogeneous deposition (Fig. 1). The use of the soluble reagent $\mathrm{NaCl}, \mathrm{KCl}, \mathrm{CaCl}_{2}$ leads to the gradual formation of sediment and its crystallization not locally but throughout the reaction volume (Fig. 2). The initial particles of sediment carry out effective sorption of impurities of metal ions, which are removed by increased sediment of a crystalline shape with high filtration characteristics.

Existing and known methods of using magnesium hydroxocomplexes solutions as a reagent were not used before and were not known from the available literary sources. We believe that the research in this area is pioneering. The proposed technology was issued a patent of Ukraine for the invention [23].

The caveat of this research is the need for a more thorough study of the properties of sediment at the stages of its formation, as well as its sorption capacity in solutions to several metal ions in exceptionally valuable technologies. We believe that such studies will be continued.

One shouldestablish the composition and structure of hydrolysis forms of magnesium, features of the process of sedimentation. In practice, such studies open upthe following opportunities:

- obtaining highly pure compounds of magnesium, potassium, sodium for the pharmaceutical industry and for medicine, with the content of admixture compounds in the form of 3 -d metals no more than the value of $5 \cdot 10^{-7}$ as a percentage;

- devising an effective technology for treatingthe solutions and industrial wastewater from toxic and active metals, including radioactive substances, fire-resistant articles;

- creating the basis of technology of extraction and concentration of liquid and scattered metals for the needs of the latest technology.

The result of our studies is the proposal to use auxiliary reagents, not of extraneous nature and composition, but only those that are genetically related to raw materials with the sediment agent being a solution of hydrolyzed forms of magnesium in its chloride. In practice, such techniques are simple and not energy-consuming, and easy to execute.

Another very important result is to ensure the quality and reliability of results in establishing the content of metal ions in various objects by the methods of neutron-activation, $\mathrm{X}$-ray-fluorescent, and atomic-absorption analyses. During 
analyses, it is very important that the matrix collector does not have the content of impurity metal ions, which can lead to false test results. Based on a highly pure matrix of magnesium hydroxide, it is possible to manufacture reference samples for laboratory tests of various types of articles and to verifyprocedures for conducting chemical analyses.

Our experiments confirmed that it is possible to achieve high chemosorptional properties of magnesium hydroxide to most ions of impurity metals and the formation of magnesium sorbent hydroxide with high filtration properties during the deposition of the crystalline structure of magnesium sorbent. The results and their numerical values show the effectiveness of the proposed technology. The practical aspect of the proposed technology relates, for example to the following:

- for extraction from solutions of especially rare concentrating elements and extraction of rare earth compounds of lanthanoid group;

- or treating solutions and industrial wastewaters from toxic and active metals that are easily filtered on magnesium hydroxide.

- to obtain highly pure compounds for medical purposes;

- to create heat-resistant plastics and fire-protectivearticles, which is especially important in modern high-rise construction.

Our results related to obtaining hydrolyzed magnesium forms in the form of solutions of its hydroxocomplexes make it possible to apply them to obtain a highly effective collector of impurity 3-d metals with a high filtration coefficient, which has significant advantages compared to foreign sorbents that were used in $[7,8]$. Unlike the use of foreign substances as a sorbent collector, the principle of formation of a sediment collector by the method of "Emerging reagent" makes it possible to use a chemically related sorption material. Such application is quite simple in terms of the chemical nature of reagents and technological procedures since it is effective in cleaning solutions (Tables 1,2), as well as in terms of the filtration properties of the sediment (Fig. 7).

The proposed solution for the formation of solutions of magnesium hydroxocomplexes and the use of them as a reagent to obtain magnesium hydroxide sediment according to the "Emerging Reagent" method is new in the area of research into the technology of magnesium compounds. Therefore, we have accomplished our goal to obtain highly pure magnesium compounds and receive its hydroxide sediment as a collector for impurities of 3 -d metals.

The limitations of the proposed technology include the need to use highly concentrated solutions of magnesium chloride at the stage of obtaining hydroxocomplexes.

During the experiments, we have not been able to deeply study the structure of the formation of magnesium hydroxide based on theembryo and primitive particles and the possi- bility of programming and controlling this process at the crystallization stage.

The current research can be advanced using the method of concentration and isolation from solutions of scattered and liquid metals, which are highly needed for new technologies.

\section{Conclusions}

1. Our study into the hydrolysis of magnesium ions in a wide range of concentrations has established that the primary product of hydrolysis is magnesium hydroxide in the labile (active) form. At a magnesium chloride concentration larger than $1 \mathrm{~mol} / \mathrm{dm}^{3}$, the labile form of hydroxide interacts with magnesium chloride and forms soluble hydroxocomplexes.

2. When a solution of hydroxocomplexesis diluted with water or a weak solution of magnesium chloride, according to the method of emerging reagents, the sediment of its hydroxide is formed. The formation of magnesium hydroxide sediment takes place gradually according to the scheme of homogeneous deposition: embryos $\rightarrow$ primaryparticles $\rightarrow$ crystals. The crystals themselves are formed from primary nanoparticles measuring $40-60 \mathrm{~nm}$.

3 . The embryos and primary particles are the most sorption active to $3 \mathrm{~d}$ metal ions, irreversible sorption remains in the formation of sediment crystals, the degree of concentration is $1 \cdot 10^{4}$ times.

4. The formation of crystals measuring $1000-4000 \mathrm{~nm}$ can significantly increase the filtration process from the uterine solution. The filtration factor increases from $K_{f}=8 \cdot 10^{-9} \mathrm{~m} / \mathrm{h}$ to $K_{f}=8 \cdot 10^{-3} \mathrm{~m} / \mathrm{h}$.

Our research results are suitable for technologies for obtaining highly pure magnesium compounds from various types of raw materials containing magnesium ions. Underlying the proposed technology is the application of the concentrated solutions of magnesium chloride hydrolyzed with alkali and saturated with magnesium hydroxocomplexes. The difference in technologies is combining different methods of their use (dilution) depending on the concentration of magnesium in the raw material or already in the purified solution of magnesium salt.

\section{Acknowledgments}

We express our sincere gratitude to Doctor of Chemical Sciences, Professor Valery Pavlovich Antonovich for his attention to the relevance of this research and friendly advice, as well as to the lecturer with a master's degree, Vyacheslav MikhailovichSychov, who took an active part in the design of this article's drawings in accordance with the requirements of the editorial board.

References

1. Pozin, M. E. (1974). Tehnologiya mineral'nyh soley (udobreniy, pesticidov, promyshlennyh solej, okislov i kislot). Ch. 1. Leningrad: Himiya, 792.

2. Gidroksid magniya v tehnologii XXI veka. Available at: https://polit.ru/article/2015/07/07/nikohim/

3. Gidroksid magniya: tehnologii i proizvodstvo (2008). Evraziyskiy himicheskiy rynok, 3 (39), 102-119. Available at: http://www. chemmarket.info/files/demo_articles/demo_article_1236357268.pdf

4. Kovalenko, V., Kotok, V. (2018). Influence of ultrasound and template on the properties of nickel hydroxide as an active substance of supercapacitors. Eastern-European Journal of Enterprise Technologies, 3 (12 (93)), 32-39. doi: https:// doi.org/10.15587/1729-4061.2018.133548 
5. Akchurin, T. K., Savchenko, A. V., Drobin, I. Ju. (2019). Izuchenie processa osazhdenie gidroksida magniya iz bishofita. Sbornik statey mezhdunarodnoy nauchno-prakticheskoy konferencii: aktual'nye problemy i perspektivy razvitiya stroitel'nogo kompleksa. Volgogradskiy gosudarstvennyi tehnicheskiy universitet, 253-257. Available at: https://www.elibrary.ru/item.asp?id=41745295

6. PNST 65-2015. Nanostructured magnesium hydroxide. Specifications.Available at: https://docs.cntd.ru/document/1200130786

7. Matsukevich, I. V., Krutko, N. P., Ovseenko, L. V., Polhovskaja, O. V., Hubitski, D. V., Vashook, V. V. (2018). Effect of preparation method on physicochemical properties of nanostructured $\mathrm{MgO}$ powder. Proceedings of the National Academy of Sciences of Belarus, Chemical Series, 54 (3), 281-288. doi: https://doi.org/10.29235/1561-8331-2018-54-3-281-288

8. Ruchec, A. N., Besarab, S. V., Macukevich, I. V. Adsorbcionnye svojstva nanostrukturirovannyh poroshkov $\mathrm{Mg}(\mathrm{OH})_{2}$ i $\mathrm{MgO}$. Available at: https://rep.bntu.by/bitstream/handle/data/40450/Adsorbcionnye_svojstva_nanostrukturirovannyh_poroshkov_ Mg_OH_2_I_MgO.pdf

9. Umar, A., Hahn, Y.-B. (2010). Metal Oxide Nanostructures and Their Applications. American Scientific Publishers. Available at: https://www.scirp.org/(S(czeh2tfqw2orz553k1w0r45))/reference/referencespapers.aspx? referenceid=788438

10. Saoud, K. M., Saeed, S., Al-Soubaihi, R. M., Bertino, M. F. (2014). Microwave Assisted Preparation of Magnesium Hydroxide Nano-sheets. American Journal of Nanomaterials, 2 (2), 21-25. Available at: http://www.sciepub.com/abstract/abstract. aspx?id=AJN\&num=3109

11. Belyaev, S. N., Panteleev, S. V., Ignatov, S. K., Razuvaev, A. G. (2016). Structural, electronic, thermodynamic and spectral properties of Mgn ( $\mathrm{n}=2-31$ ) clusters. A DFT study. Computational and Theoretical Chemistry, 1079, 34-46. doi: https://doi.org/10.1016/ j.comptc.2016.01.011

12. Au, M. (2005). Hydrogen storage properties of magnesium based nanostructured composite materials. Materials Science and Engineering: B, 117 (1), 37-44. doi: https://doi.org/10.1016/j.mseb.2004.10.017

13. Snehyrov, V. P., Iakovlieva, L. V., Snehyrova, D. V., Almacaeva, L. G. (2017). Magnesium compounds: medicines, their consumption and prospects of a new drug production part 1. 100 magnesium containing medicines of the ukrainian pharma-ceutical market. Vestnik farmacii, 4 (78). Available at: https://vestnik-pharm.vsmu.by/rezyume/vestnik-farmatsii-2017-4-78

14. Renthenofluorestsentnyi analiz. Available at: https://www.laboratuar.com/uk/testler/kimyasal-testler/x-ray-floresan-analizi/

15. Kolomiets, L. V., Sychev, M. I., Boriak, K. F. (2016). Method of preparation phantom for calibration of magnetic resonance equipment. Collection of scientific works of the Odesa State Academy of Technical Regulation and Quality, 2 (9), 45-47. doi: https://doi.org/10.32684/2412-5288-2016-2-9-45-47

16. Metody koncentrirovaniya veshhestv v analiticheskoy himii (2005). Trudy komisii po analiticheskoy himii. Vol. 25. Moscow: Izd-vo AN RF, 394.

17. Chursin, V. I., Panfilov, E. V. (2019). Precipitation of chromium-containing tanning solution of suspension magnesium hydroxide. Izvestiya vysshikh uchebnykh zavedenii khimiya khimicheskaya tekhnologiya, 62 (9), 110-116. doi: https://doi.org/10.6060/ ivkkt.20196209.5918

18. Komarov, V. S. (2013). Nauchnye osnovy sinteza adsorbentov. Minsk: Belarus. navuka, 181.

19. Khazyn, E. F., Konopchuk, T. Y., Horonovskyi, Y. F., Sheka, Y. A. (1980). Nauchni osnovy syntezu sorbentiv. Ukrainskyi khimichnyi zhurnal, 46 (7), 720.

20. Mirzakulov, K., Bobokulova, O., Tojiev, R.(2017). Research of processes of evaporation and filtrations cleared leaches of lakes Karaumbet and Barsakelmes. Universum: tehnicheskie nauki: elektron. nauchn. zhurn., 8 (41). Available at: https://7universum. $\mathrm{com} / \mathrm{ru} / \mathrm{tech} / \mathrm{archive} / \mathrm{item} / 5059$

21. Husnutdinov, V. A. (2000). Fiziko-himicheskie osnovy tehnologii pererabotki netradicionnogo magnezial'nogo syr'ja na chistyi oksid i drugie soedineniya magniya. Kazan'. Available at: https:/www.dissercat.com/content/fiziko-khimicheskie-osnovytekhnologii-pererabotki-netraditsionnogo-magnezialnogo-syrya-na-c

22. Vasserman, I. M. (1980). Himicheskoe osazhdenie iz rastvorov. Leningrad: Himiya, 207.

23. Kudrjavcev, P. G. (2018). Gomogennoe osazhdenie gidratirovannogo oksida i ego primenenie dlya polucheniya kompozicionnyh materialov. Inzhenerniy vestnik Dona, 3. Available at: http://ivdon.ru/uploads/article/pdf/IVD_267_Kudryavtsev.pdf_9b3d7015de.pdf

24. Gomogennoe osazhdenie. Spravochnik himika. Vol. 21. Himiya i himicheskaya tehnologiya. Available at: https://www.chem21.info/ info/9925/

25. Vinogradova, E. N. (1951). Vliyanie temperatury i koncentracii soli na rN pri osazhdenii gidroksida magniya. Trudy komisii po analiticheskoy himii. Vol. III (V. I0). Moscow: Izd-vo AN SSSR, 138-145.

26. Lur'e, Ju. Ju. (1979). Spravochnik po analiticheskoy himii. Moscow: Himiya, 480.

27. Enander, I., Villadsen, J. V., Sillén, L. G., Sillén, L. G., Zaar, B., Diczfalusy, E. (1958). Experiments with Methyl-fluoro-phosphorylcholineinhibited Cholinesterase. Acta Chemica Scandinavica, 12, 780-781. doi: https://doi.org/10.3891/acta.chem.scand.12-0780

28. Juhnevich, G. V. (1973). Infrakrasnaja spektroskopiya vody. Moscow: Nauka, 208.

29. Vedeneev, V. I., Gurvich, L. V., Kondrat'ev, V. N. i dr. (1962). Energiya razryva himicheskih sviazey. Leningrad: Izd-vo AN SSSR, 215.

30. Lazareva, A. I., Bulavina, M. O. (Eds.) (1980). Kolebaniya okisnyh reshetok. Moscow: Nauka, 365.

31. Balicheva, T. G., Lobaneva, O. A. (1983). Jelektronnye i kolebatel'nye spektry neorganicheskih i koordinacionnyh soedineniy. Leningrad: Izd vo LGU, 117.

32. Kolin'ko, P. A., Kozlov, D. V.(2013). Himicheskaya kinetika v kurse fizicheskoy himii. Novosibirsk, 99. Available at: https://nsu.ru/xmlui/ bitstream/handle/nsu/712/Химическая\%20кинетика\%20в\%20курсе\%20физической\%20химии.pdf?sequence=3\&isAllowed=y 